\title{
Serial measurements of exhaled nitric oxide during exacerbations of chronic obstructive pulmonary disease
}

\author{
A.G.N. Agustí, J.M. Villaverde, B. Togores, with the technical collaboration of M. Bosch
}

\begin{abstract}
Serial measurements of exhaled nitric oxide during exacerbations of chronic obstructive pulmonary disease. A.G.N. Agustí, J.M. Villaverde, B. Togores. (C) ERS Journals Ltd 1999. ABSTRACT: Excessive inflammation seems important in chronic obstructive pulmonary disease (COPD), particularly during exacerbations of the disease. Exhaled nitric oxide concentration ([NOexh]) is a sensitive marker of bronchial inflammation in asthma; it is unclear if this is also the case in COPD. This study: 1) quantifies [NOexh] in patients with COPD (during an exacerbation and while clinically stable); 2 ) investigates the response of [NOexh] to i.v. steroid therapy, and its potential relationship with other relevant physiological variables; and 3) assesses the relative contributions of the central and peripheral airways to [NOexh] by collecting exhaled air in two different bags connected in series.

Seventeen COPD patients (forced expiratory volume in one second (FEV1) 37.6 $3.4 \%$ of the predicted value $( \pm$ SEM)) hospitalized because of an exacerbation of the disease (arterial oxygen tension $\left(P_{\left.\mathrm{a}, \mathrm{O}_{2}\right)}(7.46 \pm 0.72 \mathrm{kPa} 56.1 \pm 5.4 \mathrm{mmHg})\right.$, arterial carbon dioxide tension $\left.\left.\left(\mathrm{Pa}_{1} \mathrm{CO}_{2}\right) 5.63 \pm 0.37 \mathrm{kPa} 42.3 \pm 2.8 \mathrm{mmHg}\right), \mathrm{pH} 7.41 \pm 0.02\right)$ and 10 healthy subjects that served as controls were studied.

On admission, [NOexh] in COPD was higher than normal $(41.0 \pm 5.1$ versus $13.3 \pm 0.8$ parts per billion (ppb), respectively, $\mathbf{p}<\mathbf{0 . 0 0 1}$ ). Despite $i . v$. steroid therapy, [NOexh] remained elevated throughout recovery $(37.9 \pm 4.8 \mathrm{ppb}, \mathrm{p}<0.001)$ until discharge $(40.9 \pm 4.3 \mathrm{ppb}, \mathrm{p}<\mathbf{0 . 0 0 1})$. In contrast, when the patients were clinically stable (several months later), [NOexh] was significantly reduced $(15.8 \pm 3.8 \mathrm{ppb}, \mathrm{p}<0.001)$, and no longer different from control values. [NOexh] was not related to any of the physiological variables measured during recovery (pulmonary gas exchange) or at discharge (forced spirometry, lung volumes, diffusing capacity). Finally, the contribution of the central and peripheral airways to [NOexh] was not different at any point in time.

These results indicate that during exacerbations of chronic obstructive pulmonary disease, the exhaled nitric oxide concentration: 1) is higher than normal; 2) is not reduced acutely by $i . v$. steroids but is normalized several months after discharge; 3 ) is unrelated to several physiological indices of disease severity; and 4) appears to be produced homogeneously in central and peripheral airways. Overall, these results are different from those reported in asthma, suggesting that different inflammatory mechanisms are operating in both diseases.
\end{abstract}

Eur Respir J 1999; 14: 523-528.

Servei de Pneumologia and Unitat d'investigació, Hospital Universitari son Dureta, Palma de Mallorca, Spain.

Correspondence: A.G.N. Agustí

Servei Pneumologia

Hospital Univ. Son Dureta

Andrea Doria 55

07014 Palma

Mallorca

Fax: 34971175228

\section{Keywords: Asthma}

chronic obstructive pulmonary disease inflammation

nitric oxide

respiratory failure

Received: August 211998

Accepted after revision June 231999

Supported, in part, by ABEMAR.
Patients with uncontrolled bronchial asthma show increased exhaled nitric oxide concentration ([NOexh]) [1]. Treatment with steroids rapidly reduce these back to normal levels, both in the outpatient setting $[1,2]$ and during hospitalization because of an acute asthma attack [3]. Currently, ([NOexh]) is viewed as a marker of pulmonary inflammation in asthma [4].

Excessive inflammation also appears to play an important pathogenic role in chronic obstructive pulmonary disease (COPD) [5-7], particularly during exacerbations $[8,9]$. Yet, there is little information available regarding [NOexh] in COPD. Two recent studies showed that, at variance with asthma, [NOexh] in patients with stable COPD was minimally elevated compared to normal values and that, interestingly, the response to inhaled steroids was almost negligible $[10,11]$. To date, however, there has been no systematic attempt to quantify [NOexh] in patients hospitalized because of an acute exacerbation of
COPD, in which there is a burst of inflammatory mechanisms $[8,9]$, nor to assess [NOexh] serially during recovery, study its response to $i . v$. steroids $[12,13]$ or analyse its potential relationship with other physiological indexes of disease severity. Further, there is ongoing debate as to whether inflammation in COPD occurs mainly in central versus peripheral airways $[14,15]$. It was reasoned that the use of two different bags to collect serially the exhaled air in these patients may allow the partitioning of [NOexh] in gas coming mainly from the central (first bag) or peripheral airways (second bag), in a manner quite similar to that used in the single-breath diffusing capacity of the lung for carbon monoxide DL,CO measurement [16].

Accordingly, the aim of this study was to: 1) determine [NOexh] serially (on admission, during recovery, at discharge and while clinically stable) in a group of patients hospitalized because of an acute exacerbation of COPD and treated with i.v. steroids; 2) investigate the relationship 
between [NOexh] and other variables of potential physiological interest, such as the severity of respiratory failure or the degree of airflow obstruction; and, 3) dissect the relative contribution of central and peripheral airway inflammation to [NOexh] in these clinical circumstances.

\section{Material and methods}

\section{Study subjects}

Seventeen male COPD patients (68.2 \pm 2.6 yrs (SEM)) who required hospitalization because of an exacerbation of the disease were studied. All of them had a significant smoking history (>30 pack-yrs); two were current smokers. In the emergency room, all had acute respiratory failure (arterial oxygen tension $\left(\mathrm{Pa}_{\mathrm{a}} \mathrm{O}_{2}\right) 7.46 \pm 0.72 \mathrm{kPa}(56.1 \pm$ $5.4 \mathrm{mmHg})$; arterial carbon dioxide tension $\left(P \mathrm{a}, \mathrm{CO}_{2}\right) 5.63 \pm$ $0.37 \mathrm{kPa}(42.3 \pm 2.8 \mathrm{mmHg}) ; \mathrm{pH} 7.41 \pm 0.02)$ and, at discharge, all had severe airflow obstruction (forced expiratory volume in one second (FEV1) $1.02 \pm 0.11 \mathrm{~L}, 37.6 \pm$ $3.4 \%$ of the predicted value). None of them suffered from any other concomitant disease that could potentially interfere with the diagnosis and/or clinical course. In particular, asthma, pneumonia, heart failure and cancer were specifically excluded on the basis of standard clinical, radiological and biochemical tests. During hospitalization, treatment was standardized and included oxygen, nebulized bronchodilators and i.v. steroids (methylprednisolone $40 \mathrm{mg} \cdot 8 \mathrm{~h}^{-1}$ ). From day $4-5$, steroids were individually tapered by physicians not directly involved in the study. All patients were successfully discharged. At that point, treatment was indicated by the physician in charge. It normally included bronchodilators $\left(\beta_{2}\right.$-agonists and/or anticholinergics) and inhaled steroids. A group of 10 healthy male nonsmoker volunteers (33.1 $\pm 1.5 \mathrm{yrs})$ who served as controls were also studied. All participants signed their written consent after being fully informed of the nature, characteristics, risks and potential benefits of the study. This study was approved by the Research and Ethical Review Board of the Hospital Universitari Son Dureta.

\section{Study design}

During hospitalization, [NOexh] (and arterial blood gas levels) were measured at three different time points: within 24-48 h of hospital admission, on day 4-5 after admission, and at discharge (usually on day 9-10). Measurements were always obtained at the same time of day ( 09:00). Arterial blood gas concentrations were measured while the patient was breathing the oxygen concentration that the physician in charge thought was needed (generally 24-28\% via a Venturi mask (Proclinico ${ }^{\mathbb{}}$; Montmeló, Barcelona, Spain). Conversely, in order to avoid any potential effect of oxygen therapy on [NOexh] [17-19], this was measured while breathing room air, at least $30 \mathrm{~min}$ after having stopped oxygen therapy. During this time, arterial oxyhaemaglobin saturation was continuously monitored (Criticare Systems, Inc., Waukesha, WI, USA). Each collection of expired gas (and measurement of [NOexh]) was performed in triplicate. Since these three measurements were not statistically different, their mean value was later used for analysis.
Originally, it was planned to study these same 17 patients while clinically stable. However, it was only possible to study 10 of them after hospitalization (three were studied at 1-2 months after discharge; the rest were studied at 6-8 months after hospitalization). Of the remaining seven patients, three individuals refused to return to the laboratory and four subjects no longer lived in the same area.

\section{Methods}

In order to measure [NOexh] the patient was asked to perform a slow vital capacity manoeuvre over $30-75 \mathrm{~s}$ into a high-resistance small diameter $(4 \mathrm{~mm})$ Teflon tubing system. This prevents contamination with NO from the nose cavity [20]. Similarly to in the measurement of $D$ L,CO in clinical practice [16], this tubing system was connected through a two-way stopcock to two polyethylene bags of different size. The first $\sim 500 \mathrm{~mL}$ of expired gas were collected in the first bag (Warren E. Collins, Braintree, MA, USA), which probably contains mainly gas from the upper and central airways (bagcaw). Without interrupting the exhalation, by switching the stopcock, the rest of the exhaled gas was collected in the second bag (Intertech Rx DABC; Mallinckrodt, Mirandola, Italy), which probably contains mainly gas from the peripheral airways (bagpaw). Both bags were assayed immediately ( $<10 \mathrm{~min}$ ) after sampling for NO concentration using a chemiluminescence analyser (Dasibi Environmental Corporation, Glendale, CA, USA) sensitive to NO at 2-4,000 parts per billion (ppb, by volume). This analyser has been used by previous investigators in the field [1]. The analyser was connected to a personal computer through appropriate software (Atlantis; Lakeshore Technologies, Chicago, IL, USA), which displayed the results on-line and stored them for later analysis (Pegasus; Lakeshore Technologies). The NO analyser was calibrated before analyses with certified gas mixtures $(300 \mathrm{ppb}$ NO diluted in nitrogen by precision flow meters) (Abello Oxígeno Linde, Barcelona, Spain). The concentration of NO in ambient air (typically $<10 \mathrm{ppb}$ in Palma de Mallorca) was measured and subtracted from each NO determination. The analysis of both bags took $<10 \mathrm{~min}$ in all cases. Preliminary experiments in the authors' laboratory have determined the stability of NO concentrations far beyond this time $(>30 \mathrm{~min})$. This is in keeping with previous reports from other laboratories [10]. Also, to ensure that NO did not react with the materials that the collecting bags were made of, pilot studies compared measurements obtained after passing NO calibration gas through the tubing, connections or bags with those obtained after introducing the NO calibration gas directly into the NO analyser. These studies failed to demonstrate any significant decrease in NO concentration.

Arterial blood gas concentrations were measured in patients with COPD after radial artery puncture and local anaesthesia in a tonometrically calibrated (IL 237; Izasa, Spain) analyser (IL BG3; Izasa, Barcelona, Spain). The alveolar-arterial pressure difference for oxygen $\left(P \mathrm{~A}-\mathrm{a}, \mathrm{O}_{2}\right)$ was calculated using the standard formula, assuming a respiratory quotient $(R)$ value of 0.8 [16]. Forced spirometry (GS system, Collins, USA) was performed (at discharge) according to American Thoracic Society (ATS) recommendations [21]; static lung volumes (helium-dilution 
Table 1. - Exhaled nitric acid concentrations ([NOexh]) in the two collecting bags from patients with chronic obstructive pulmonary disease (COPD) (throughout hospitalization and while clinically stable) and from healthy controls

\begin{tabular}{lccccc}
\hline & \multicolumn{4}{c}{ [NOexh] } \\
\cline { 2 - 5 } & \multicolumn{4}{c}{ COPD } & Healthy volunteers \\
\cline { 2 - 5 } & $24-48 \mathrm{~h}$ & $4-5$ day & Discharge & Stable & 10 \\
Subjects n & 17 & 17 & 17 & 10 & $12.9 \pm 0.6$ \\
Bagcaw & $41.5 \pm 3.4^{* *,+}$ & $38.9 \pm 3.2^{* *,+}$ & $41.8 \pm 2.9^{* *,+}$ & $16.0 \pm 4.1$ & $13.6 \pm 0.8$ \\
Bagpaw & $40.8 \pm 3.3^{* *,+}$ & $36.9 \pm 3.1^{* *,+}$ & $40.0 \pm 3.0^{* *+}$ & $15.5 \pm 3.6$ & $13.3 \pm 0.8$ \\
Mean & $41.0 \pm 5.1^{* *,+}$ & $37.9 \pm 4.8^{* *,+}$ & $40.9 \pm 4.3^{* *+}$ & $15.8 \pm 3.8$ & \\
\hline
\end{tabular}

Data are presented as mean \pm SEM and were collected during exacerbation (24-48 h, 4-5 days, discharge) and while stable. The [NOexh] measured in the two bags were not significantly different at any point. The intra-assay coefficient of variation in [NOexh] was $30 \pm 2 \%$. Bagcaw: first collecting bag, reflecting predominantly gas from central airways; bagpaw: second collecting bag, reflecting predominantly gas from peripheral airways; ppb:parts per billion. ${ }^{* *}: \mathrm{p}<0.01$ versus healthy volunteers; ${ }^{+}: \mathrm{p}<0.01$ versus stable conditions.

technique) and single breath $D \mathrm{~L}, \mathrm{CO}$ were also measured (GS system, Warren E. Collins) using standard techniques [16]. The reference values used were those of a Mediterranean population [22-24].

\section{Analysis}

Data are shown as mean \pm SEM. Analysis of variance (followed by post hoc contrasts (Scheffe test), if appropriate) was used to investigate the statistical significance of differences. Correlations between variables of interest were analysed using the Spearman rank test. A p-value $<0.05$ was considered significant.

\section{Results}

Table 1 shows the [Noexh] in each of the two collecting bags (bagcaw and bagpaw) in patients with COPD (throughout hospitalization and while clinically stable) and in healthy controls. The concentrations in the two bags were not significantly different at any point in any group. Therefore, for further analysis, the mean concentration in the two bags was used (table 1).

In healthy subjects, [NOexh] was $13.3 \pm 0.8 \mathrm{ppb}$ (table 1 ), This value is within the range reported previously in

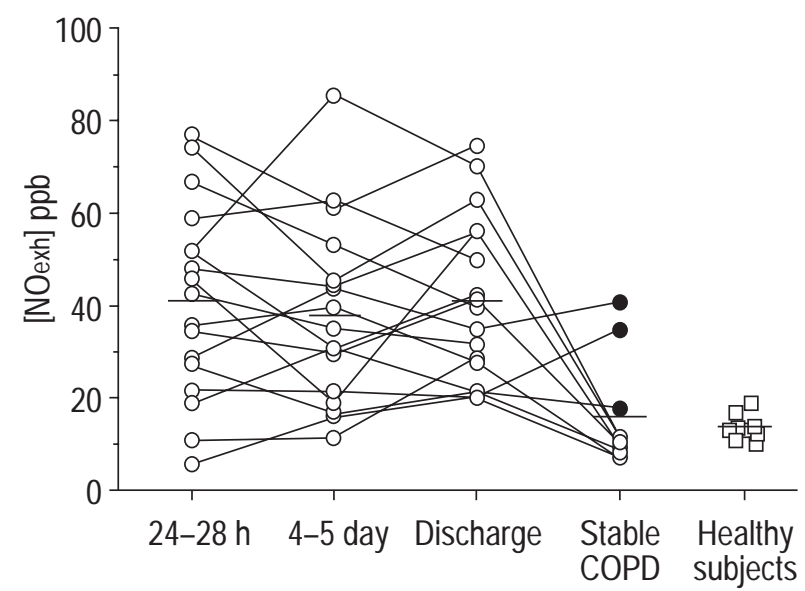

Fig. 1. - Individual and mean (horizontal bars) exhaled nitric oxide concentrations [NOexh] in patients with chronic obstructive pulmonary disease (COPD) hospitalized because of exacerbation of the disease. the three patients studied earlier after discharge, and not treated with inhaled steroids at that point in time. For further explanations, see text. ppb: parts per billion. healthy subjects, using either a collecting system similar to the one used in the present study [10] or measuring NO on-line [20].

On average, patients with COPD showed a higher [NOexh] on admission than did controls $(41.0 \pm 5.1 \mathrm{ppb}$, $\mathrm{p}<0.001)$. As shown in figure 1 , though, there was a substantial spread of [NOexh], with concentrations ranging 5.7-76.5 ppb. Interestingly, these values did not change throughout hospitalization (table 1, fig. 1). By contrast, when patients were studied in a clinically stable condition, [NOexh] was significantly lower than that measured during hospitalization (fig. 1). In fact, it was no longer different from control values (table 1). Three patients were studied earlier after discharge (at 1-2 months) than were the rest (at 6-8 months). These three patients are indicated in figure 1 . Interestingly, these three subjects seemed to have higher [NOexh] than did the rest. It should also be noted, however, that these three individuals were not being treated with inhaled steroids at that point in time, whereas the rest were. None of the 10 COPD patients studied in a stable condition was a current smoker.

As expected, pulmonary gas exchange improved during recovery (table 2). However, no significant relationship was found between [NOexh] and any of several indices of pulmonary gas exchange measured during hospitalization (fig. 2). Figure 3 depicts the [NOexh] measured in each patient at discharge plotted against several indices of lung function (also measured at discharge). Again, no significant relationship was observed.

Table 2. - Evolution of pulmonary gas exchange variables during hospitalization in all patients

\begin{tabular}{llllc}
\hline & $24-48 \mathrm{~h}$ & $4-5$ days & Discharge & p-value \\
\hline$F_{\mathrm{I}, \mathrm{O}_{2}}$ & $0.26 \pm 0.01$ & $0.25 \pm 0.09$ & $0.21 \pm 0.04^{\dagger,+}$ & 0.0001 \\
${\mathrm{~Pa}, \mathrm{O}_{2}} \mathrm{mmHg}$ & $66.8 \pm 4.8$ & $71.1 \pm 3.9$ & $65.5 \pm 2.4$ & $\mathrm{NS}$ \\
$P \mathrm{a}, \mathrm{CO}_{2} \mathrm{mmHg}$ & $43.7 \pm 2.2$ & $44.2 \pm 1.7$ & $42.1 \pm 1.5$ & $\mathrm{NS}$ \\
$\mathrm{Arterial} \mathrm{PH}$ & $7.41 \pm 0.01$ & $7.42 \pm 0.01$ & $7.43 \pm 0.01$ & $\mathrm{NS}$ \\
$P \mathrm{~A}-\mathrm{a}, \mathrm{O}_{2} \mathrm{mmHg}$ & $66.0 \pm 6.1$ & $52.7 \pm 4.8$ & $34.5 \pm 4.4^{\dagger}$, & 0.0001 \\
\hline
\end{tabular}

Data are presented as mean \pm SEM $(n=17)$ and were collected during hospitalization (24-48 $\mathrm{h}, 4-5$ days, discharge). ${ }^{\#}$ : analysis of variance. $\mathrm{FI}_{1} \mathrm{O}_{2}$ : inspiratory oxygen fraction; $P \mathrm{a}, \mathrm{O}_{2}$ :arterial oxygen tension; $\mathrm{Pa}, \mathrm{CO}_{2}$ : arterial carbon dioxide tension; $P \mathrm{~A}-\mathrm{a}, \mathrm{O}_{2}$ : alveolar-arterial pressure difference for oxygen. ${ }^{\dagger}$ : $\mathrm{p}<0.01$ versus $24-48 \mathrm{~h} ;{ }^{+}: \mathrm{p}<0.01$ versus $4-5$ days. $(1$ $\mathrm{mmHg}=0.133 \mathrm{kPa}$.) 
a)

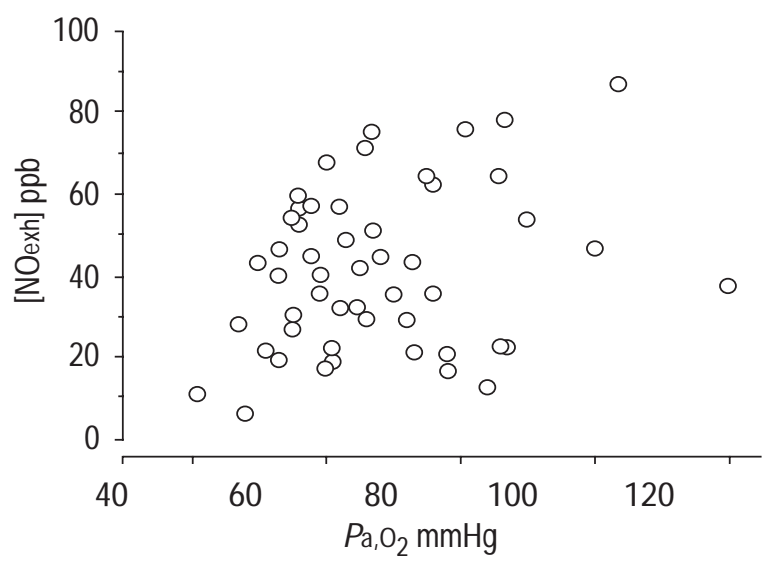

c)

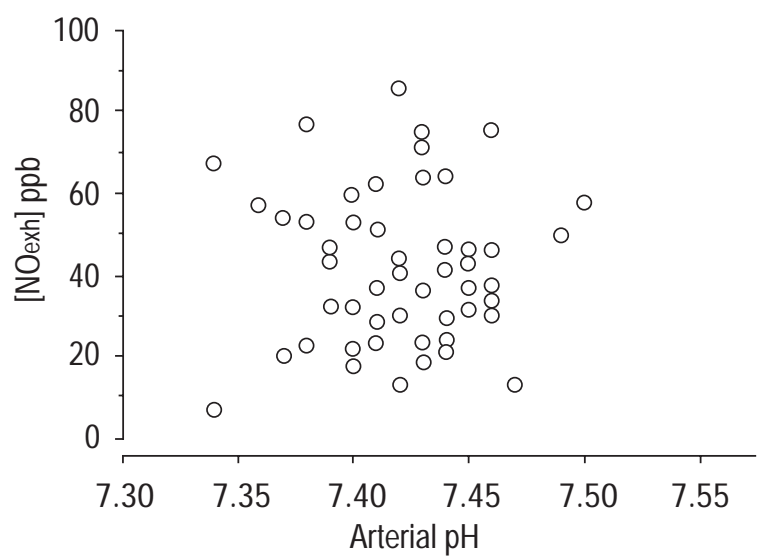

b)

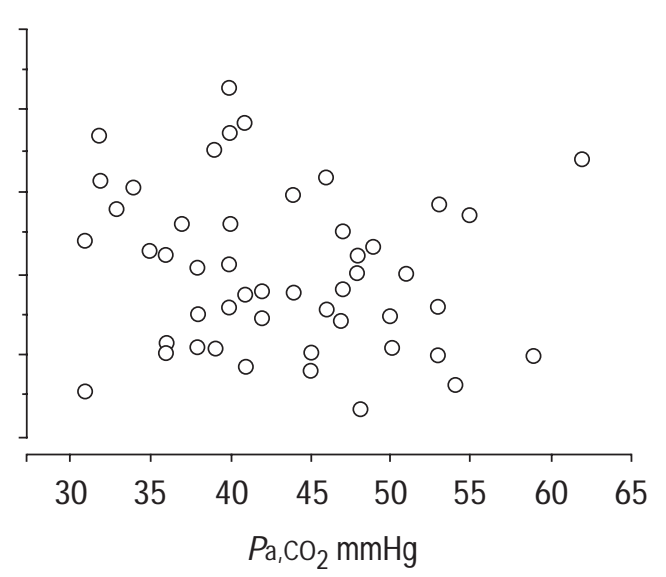

d)

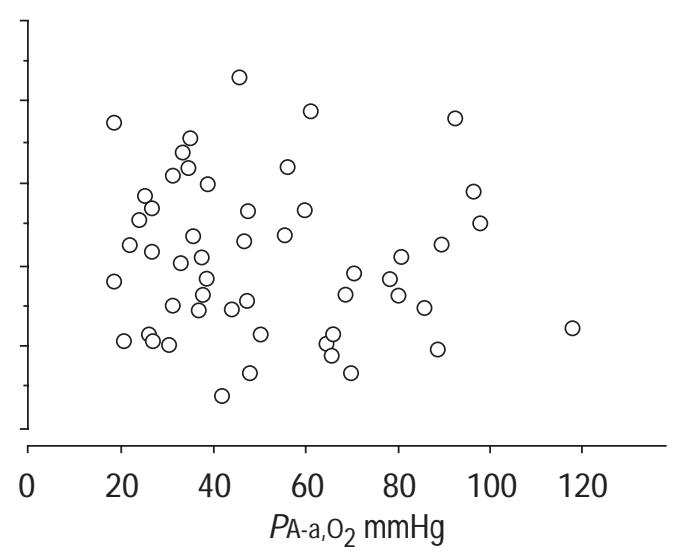

Fig. 2. - Lack of correlation between exhaled nitric acid concentration ([NOexh]) and: a) arterial oxygen tension $\left(P a, \mathrm{O}_{2}\right)$; b) arterial carbon dioxide tension $\left.\left(\mathrm{Pa}_{\mathrm{a}} \mathrm{CO}_{2}\right) ; \mathrm{c}\right)$ arterial $\mathrm{pH}$; and $\left.\mathrm{d}\right)$ alveolar-arterial pressure difference for oxygen $\left(P \mathrm{~A}-\mathrm{a}, \mathrm{O}_{2}\right)$ (including all measurements obtained during the hospital stay in all patients $(\mathrm{n}=17))$. For further explanations, see text. ppb: parts per billion. $(1 \mathrm{mmHg}=0.133 \mathrm{kPa}$.)

\section{Discussion}

The main findings of this study were that, in patients with severe COPD hospitalized because of an acute exacerbation of the disease, the [NOexh] 1) is significantly higher than normal; 2) is neither modulated during hospitalization, nor appears to be influenced by $i . v$. treatment with steroids (in contrast, it is normalized several months later, when patients are considered clinically stable); 3) does not correlate with several lung function variables measured during hospitalization or at discharge; and, 4) is not different in the first and second collecting bags, suggesting that it is not different in air samples coming from the central or the peripheral airways.

Previous studies have established that [NOexh] is a sensitive and reproducible marker of pulmonary inflammation in patients with bronchial asthma $[1,3,10,25,26]$. Much less information is available in patients with COPD $[10,11]$. The present study is the first to report serial [NOexh] in patients hospitalized because of exacerbated COPD. In these clinical circumstances, a burst of inflammatory mechanisms is supposed to operate [5-9]. In keeping with this postulate, it was found that many patients with exacerbated COPD had higher [NOexh] than did healthy nonsmoking subjects (table 1) [3, 10], although the spread of values was significant (fig. 1). Interestingly, despite the use of i.v. steroids [NOexh] remained higher than normal throughout hospitalization (table 1, fig. 1).
This is at variance with what has been reported in patients with asthma $[1,3,10,25,26]$ but in agreement with what seems to occur in stable COPD $[10,11]$. Different responses to steroid treatment in asthma and COPD have also been shown in several inflammatory indexes in induced sputum [6]. Overall, thus, these observations suggest that the inflammatory mechanisms inducing the expression of NO synthase in acute asthma and exacerbated COPD are probably different [27-29]. It is also worth noting that the [NOexh] measured in COPD were almost identical in the two collecting bags used at any point in time (table 1). Although the present two-bag method has not been formally validated for the partitioning of exhaled NO, by analogy to $D \mathrm{~L}, \mathrm{CO}$ measurements, which are based upon the same rationale, it seems fair to assume that the first bag probably contains gas from the central airways whereas the second bag contains gas from the peripheral airways. If this is accepted, then the present results suggest a similar contribution of the central and peripheral airways to [NOexh] in patients with COPD, and, therefore, that the inflammatory mechanisms operating in COPD are evenly distributed through the lungs.

It has been suggested that [NOexh] could be a useful surrogate marker for monitoring disease activity in stable COPD [11]. The present results indicate that this is not the case during exacerbations as, despite clinical and functional improvement (table 2), the [NOexh] remained elevated through hospitalization (table 1, fig. 1). Further, 
a)
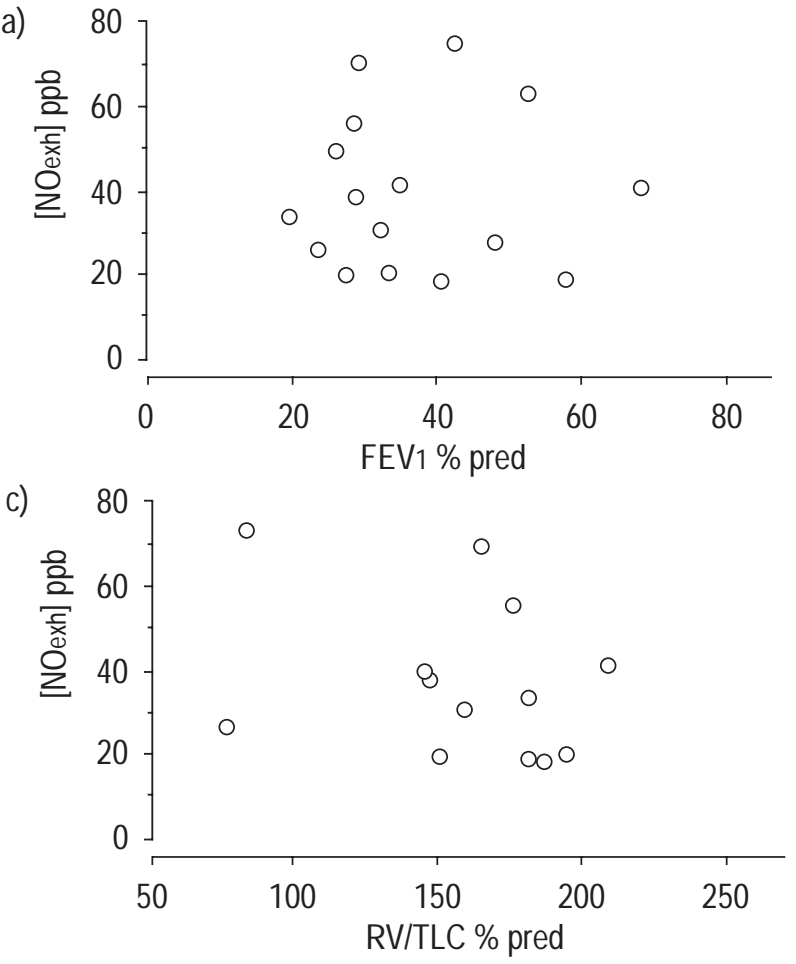

b)

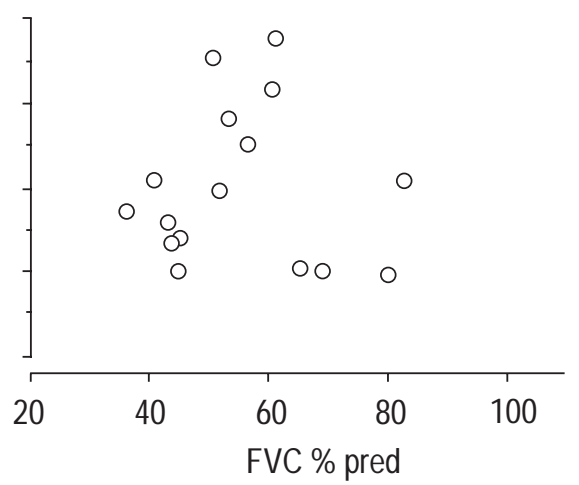

d)

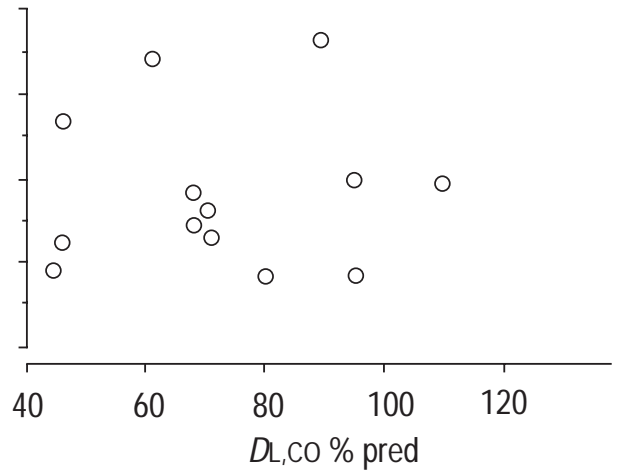

Fig. 3. - Lack of correlation between exhaled nitric acid concentration ([NOexh]) and the degree of mechanical impairment: a) forced expiratory volume in one second (FEV1); b) forced vital capacity (FVC); c) residual volume (RV)/total lung capacity (TLC); and d) diffusing capacity of the lung for carbon monoxide $(D \mathrm{~L}, \mathrm{CO})$. The measurements were obtained at discharge from hospital. ppb: parts per billion.

no significant correlation was found between [NOexh] and lung function during hospitalization (fig. 2) or at discharge (fig. 3). By contrast, it was remarkable that the [NOexh], was much lower under conditions of clinical stability (table 1, fig. 1) and, in fact, indistinguishable from that of control subjects, as reported previously [10, 11]. Overall, therefore, the present results indicate that [NOexh] is not useful in COPD in monitoring inflammation or guiding therapy during an episode of exacerbation, but it may indeed be a long-term marker of disease activity [11]. Importantly, these results also show that the correction of the inflammatory burst that characterizes an exacerbation in COPD is not immediate and may require several months. That [NOexh] was higher in those patients studied shortly after discharge (at 1-2 months) than in those assessed later on (at 6-8 months) (fig. 1) also supports this idea. An alternative explanation for this latter observation, though, is an effect of inhaled steroids upon [NOexh]. By chance, patients studied shortly after discharge were not treated with inhaled steroids, whereas the remaining subjects were (fig. 1). However, it is thought that this possibility is unlikely since i.v. steroids during hospitalization did not modify [NOexh] at all (table 1, fig. 1).

In order to avoid collecting NO in a reservoir, [NOexh] is normally measured on-line [20]. However, recent guidelines accept measurements made using a reservoir [20]. The latter approach was chosen because, first, it was of interest to dissect the relative contributions of the central and peripheral airways to [NOexh] in exacerbated COPD and, secondly, because it greatly facilitates the measurement of [NOexh] at the bedside. Other investigators in the field have previously used a similar system to assess the progression of [NOexh] during an episode of acute severe asthma [3]. The authors are confident that the methodol- ogy used did not influence the results. 1) As discussed in Methods, it had previously been ensured that NO readings did not change significantly within the period of time required for the analysis, and that NO did not react with the materials that the bag was made of. 2) The same system was used repeatedly to measure the [NOexh] in the patients during the progression of the disease. Therefore, the patients effectively acted as their own controls. 3) Previous studies have shown that [NOexh] are qualitatively independent of the technique used [10]. 4) Finally, the [NOexh] measured in the present study in healthy nonsmoking volunteers (table 1) are in keeping with previous published studies that used similar collecting systems $[3,10]$.

In summary, the present study shows that, during exacerbations of chronic obstructive pulmonary disease, the exhaled nitric oxide concentration is higher than normal, despite the use of intravenous steroids it remains elevated throughout hospitalization and it is not until several months after discharge that it normalizes fully. Further, it was found that, in the patients studied, the contribution of the central and peripheral airways to exhaled nitric oxide concentration was quite similar, suggesting that inflammation is distributed uniformly through the lungs in exacerbated chronic obstructive pulmonary disease. Overall, these results differ from those reported in asthma, further supporting the concept that the inflammatory mechanisms underlying chronic obstructive pulmonary disease and asthma are different.

Acknowledgements. The authors thank the nursing personnel of the Servei de Pneurnologia (Hospital Son Dureta, Palma de Mallorca, Spain) for their help and collaboration during this study. 


\section{References}

1. Kharitonov SA, Yates D, Robbins RA, Logan-Sinclair R, Shinebourne EA. Barnes PJ. Increased nitric oxide in exhaled air of asthmatic patients. Lancet 1994; 343: 133135.

2. Kharitonov SA, Yates DH, Chung KF, Barnes PJ. Changes in the dose of inhaled steroid affect exhaled nitric oxide levels in asthmatic patients. Eur Respir $J$ 1996; 9: 196-201.

3. Massaro AF, Gaston B, Kita D, Fanta C, Stamler JS, Drazen JM. Expired nitric oxide levels during treatment of acute asthma. Am J Respir Crit Care Med 1995; 152: 800-803.

4. Barnes PJ, Kharitonov SA. Exhaled nitric oxide: a new lung function test. Thorax 1996; 81: 233-237.

5. Di Stefano A, Turato G, Maestrelli P, et al. Airflow limitation in chronic bronchitis is associated with $\mathrm{T}$ lymphocyte and macrophage infiltration of the bronchial mucosa. Am J Respir Crit Care Med 1996; 153: 629-632.

6. Keatings VM, Barnes PJ. Granulocyte activation markers in induced sputum: comparison between chronic obstructive pulmonary disease, asthma, and normal subjects. $\mathrm{Am}$ J Respir Crit Care Med 1997; 155: 449-453.

7. O'Shaughnessy TC, Ansari TW, Barnes NC, Jeffery PK Inflammation in bronchial biopsies of subjects with chronic bronchitis: inverse relationship of CD8+ T lymphocytes with FEV1. Am J Respir Crit Care Med 1997; 155 852-857.

8. Rahman I, Skwarska E, MacNee W. Attenuation of oxidant/antioxidant imbalance during treatment of exacerbations of chronic obstructive pulmonary disease. Thorax 1997; 52: 565-568.

9. Selby C, Drost E, Lannan S, Wraith PK, MacNee W. Neutrophil retention in the lungs of patients with chronic obstructive pulmonary disease. Am Rev Respir Dis 1991; 143: 1359-1364.

10. Robbins RA, Floreani AA, Von Essen SG, et al. Measurement of exhaled nitric oxide by three different techniques. Am J Respir Crit Care Med 1996; 153: 16311635

11. Maziak W, Loukides S, Culpitt S, Sullivan P, Kharitonov SA, Barnes PJ. Exhaled nitric oxide in chronic obstructive pulmonary disease. Am J Respir Crit Care Med 1998; 157: 998-1002.

12. Siafakas NM, Vermeire P, Pride NB, et al. Optimal assessment and management of chronic obstructive pulmonary disease (COPD). European Respiratory Society consensus statement. Eur Respir J 1995; 8: 1398-1420.

13. Celli B, Snider GL, Heffner J, et al. Standards for the diagnosis and care of patients with chronic obstructive pulmonary disease. Official statement of the American Thoracic Society. Am J Respir Crit Care Med 1995; 152: S77-S120.

14. Maestrelli P, Saetta M, Di Stefano A, et al. Comparison of leukocyte counts in sputum, bronchial biopsies, and bronchoalveolar lavage. Am J Respir Crit Care Med 1995; 152: 1926-1931.

15. Jeffery PK. Comparative morphology of the airway wall in asthma and in chronic obstructive pulmonary disease. Am Rev Respir Dis 1991; 143: 1152-1158.

16. Clausen JL. Pulmonary function testing. Guidelines and controversies. Equipment, methods and normal values. Grune \& Stratton, Inc., Orlando, 1984; 1-338.

17. Whorton AR, Simonds DB, Piantadosi CA. Regulation of nitric oxide synthesis by oxygen in vascular endothelial cells. Am J Physiol (Lung Cell. Mol. Physiol). 1997; 272: L1161-L1166.

18. North AJ, Lau KS, Brannon TS, et al. Oxygen upregulates nitric oxide synthase gene expression in ovine fetal pulmonary artery endothelial cells. Am J Physiol (Lung Cell. Mol. Physiol). 1996; 14: L643-L649.

19. Shaul PW, Wells LB. Oxygen modulates nitric oxide production selectively in fetal pulmonary endothelial cells. Am J Respir Cell Mol Biol 1994; 11: 432-438.

20. Kharitonov SA, Alving K, Barnes PJ. Exhaled and nasal nitric oxide measurements: recommendations. Eur Respir $J$ 1997; 10: 1683-1693.

21. American Thoracic Society Official Statement. Standardization of Spirometry. 1994 Update. Am J Respir Crit Care Med 1995; 152: 1107-1136.

22. Roca J, Sanchis J, Agustí-Vidal A, et al. Spirometric reference values for a mediterrancan population. Bull Eur Physiopathol Respir 1986; 22: 217-224.

23. Roca J, Rodriguez-Roisín R, Cobo E, Burgos F, Perez J, Clausen JL. Single-breath carbon monoxide diffusing capacity (DLCO) prediction equations for a mediterranean population. Am Rev Respir Dis 1990; 141: 1026-1032.

24. Roca J, Burgos F, Barberá JA, et al. Prediction equations for plethysmographic lung volumes. Respir Med 1998; 92: 454-460.

25. Garnier P, Fajac I, Dessanges JF, Dall'Ava-Santucci J, Lockhart A, Dinh-Xuan AT. Exhaled nitric oxide during acute changes of airways calibre in asthma. Eur Respir $J$ 1996; 9: 1134-1138.

26. Kharitonov SA, O'Connor BJ, Evans DJ, Barnes PJ. Allergen-induced late asthmatic reactions are associated with elevation of exhaled nitric oxide. Am J Respir Crit Care Med 1995; 151: 1894-1899.

27. Hamid Q, Springall DR, Riveros-Moreno V, et al. Induction of nitric oxide synthase in asthma. Lancet 1993; 342: $1510-1513$.

28. Robbins RA, Barnes PJ, Springall DR. Others U. Expression of inducible nitric oxide synthase in human bronchial epithelial cells. Biochem \& Biophy Res Comm 1994; 203: 209.

29. Yates DH, Kharitonov SA, Thomas PS, Barnes PJ. Endogenous nitric oxide is decreased in asthmatic patients by an inhibitor of inducible nitric oxide synthase. $A m J$ Respir Crit Care Med 1996; 154: 247-250. 